DOI: $10.12731 / 2070-7568-2021-10-1-106-123$

УДК 378.14:004.85

\title{
ОЦЕНКА ЭФФЕКТИВНОСТИ ОБУЧЕНИЯ ПЕРСОНАЛА: МЕТОДОЛОГИЧЕСКИЙ АСПЕКТ
}

\author{
Шендель Т.В., Яркова С.А.
}

В статье раскрыты значимость и актуальность оченки эффективности обучения персонала, рассмотрены показатели и методы изучения данного проиесса. Предметной областью исследования явилось предприятие железнодорожного транспорта - структурное подразделение ОАО «Российские железные дороги». В результате оценки эффективности обучения персонала на предприятии определень проблемь, связанные с отсутствием целеполагания в обучении. Как следствие, отсутствуют показатели и критерии измерения полученного результата, что определило объективную потребность 8 их разработке как оптимального решения для предприятий железнодорожного транспорта. В качестве показателей оченки эффективности обучения персонала определены выполнение плана обучения, затраты на обучение персонала, индекс лояльности работника, удовлетворенность руководителя обучением персонала, использование полученных знаний в профессиональной деятельности, повышение производительности труда, прочент возврата аппаратуры в гарантийный период, отказы технических средств. Особо иеенным является то, что показатели эффективности отражают возвратность финансовых вложений на обучение персонала предприятия.

Цель - оченить эффективность обучения и предложить показатели измерения полученного результата для предприятий железнодорожного транспорта.

Метод или методология проведения работы: методы теоретического исследования (анализ и синтез информации), контентанализ, аналитические и статистические методы, социологические исследования (интервью). 
Результаты: определены проблемы при оценке эффективности обучения персонала на предприятии железнодорожного транспорта, предложены показатели и критерии измерения полученного результата.

Область применения результатов: предложенные показатели и критерии оченки эффективности обучения персонала могут быть использованы на крупных предприятиях различных отраслей народного хозяйства.

Ключевые слова: предприятия железнодорожного транспорта; персонал; обучение персонала; оченка эффективности; показатели эффективности обучения; методы оценки эффективности.

\section{EVALUATING THE EFFECTIVENESS OF STAFF TRAINING: A METHODOLOGICAL ASPECT}

\section{Shendel T.V., Yarkova S.A.}

The article reveals the significance and relevance of evaluating the effectiveness of personnel training, considers the indicators and methods of studying this process. The subject area of the study was the railway transport enterprise-a structural division of JSC "Russian Railways". As a result of the evaluation of the effectiveness of personnel training at the enterprise, the problems associated with the lack of goal-setting in training are identified. As a result, there are no indicators and criteria for measuring the result obtained, which determined the objective need for their development as an optimal solution for railway transport enterprises. As indicators evaluating the effectiveness of personnel training identified the implementation of the plan of training, cost of training, the index of employee loyalty, satisfaction of the head of staff training, the use of acquired knowledge in professional activity, increase productivity, the rate of return of the equipment during the warranty period, the equipment failures. It is particularly valuable that the performance indicators reflect the return on financial investments for training the company's personnel.

Purpose - evaluate the effectiveness of training and offer indicators for measuring the results obtained for railway transport enterprises. 
Methodology: methods of theoretical research (analysis and synthesis of information), content analysis, analytical and statistical methods, sociological research (interviews).

Results: the problems in evaluating the effectiveness of personnel training at the railway transport enterprise are identified, indicators and criteria for measuring the result obtained are proposed.

Practical implications: the proposed indicators and criteria for evaluating the effectiveness of personnel training can be used at large enterprises in various sectors of the national economy.

Keywords: railway transport enterprises; personnel; personnel training; performance assessment; training performance indicators; methods for evaluating performance.

\section{Введение}

Железнодорожный транспорт играет важную роль в транспортной системе России, так как на его долю приходится наибольший процент грузовых и пассажирских перевозок.

Основным вектором развития предприятий железнодорожного транспорта является миссия, заключающаяся в «эффективном развитии конкурентоспособного на российском и мировом рынках транспортного бизнеса, ядро которого - выполнение задач национального железнодорожного перевозчика грузов и пассажиров» [5]. Реализации миссии предприятий железнодорожной отрасли способствуют стратегические цели, качественное достижение которых предполагает «необходимость обеспечения непрерывного обучения персонала» [10]. Это особенно справедливо в современных условиях, когда научно-технический прогресс значительно ускоряет устаревание профессиональных компетенций.

В этой связи неоспорима значимость и актуальность оценки эффективности обучения персонала как достижение результатов, запланированных до обучения, или их не достижение при неэффективном обучении. При этом определены проблемы, обусловленные трудоемкостью данного процесса и невозможностью в ряде случаев использовать количественные методы. В частности, Т.Н. Алек- 
сеева, оценивая эффективность обучения персонала, определила три группы трудностей. Во-первых, связанных с разработкой и использованием сложной системы критериев и показателей оценки эффективности. Во-вторых, с выявлением результатов собственно обучения и «очисткой» их от влияния иных внутренних и внешних факторов, воздействующих на персонал в процессе обучения и в процессе реализации его результатов в профессиональной деятельности. В-третьих, с определением экономической эффективности обучения персонала с учетом его целенаправленного влияния на стратегию развития предприятия с выделением эффективности неформального обучения и самообучения [2].

Далее отметим точку зрения В.М. Масловой относительно показателей оценки эффективности обучения [9], которые отражены в таблице 1.

Таблицуа 1.

Показатели оценки эффективности обучения персонала

\begin{tabular}{|c|c|c|}
\hline Критерий & Содержание & Способы оценки \\
\hline $\begin{array}{l}\text { Степень удовлет- } \\
\text { воренности участ- } \\
\text { ника обучением }\end{array}$ & $\begin{array}{l}\text { - полезностью обучения; } \\
\text { - программой и преподава- } \\
\text { телем; } \\
\text { - администрированием об- } \\
\text { учения }\end{array}$ & $\begin{array}{l}\text { - анкетирование /интервью } \\
\text { участника обучения } \\
\text { - интервью линейного ру- } \\
\text { ководителя участника об- } \\
\text { учения }\end{array}$ \\
\hline $\begin{array}{l}\text { Степень усвоения } \\
\text { учебного матери- } \\
\text { ала }\end{array}$ & $\begin{array}{l}\text { - изменение знаний, навы- } \\
\text { ков, установок и мотивации } \\
\text { участника обучения }\end{array}$ & $\begin{array}{l}\text { - анкетирование участника } \\
\text { обучения } \\
\text { - анкетирование / интервью } \\
\text { преподавателя } \\
\text { - контрольные тесты, за- } \\
\text { дания }\end{array}$ \\
\hline $\begin{array}{l}\text { Динамика резуль- } \\
\text { татов деятельно- } \\
\text { сти участника об- } \\
\text { учения }\end{array}$ & $\begin{array}{l}\text { - изменение рабочего пове- } \\
\text { дения и компетенций участ- } \\
\text { ника обучения } \\
\text { - комплексное применение } \\
\text { на практике полученных } \\
\text { знаний и навыков }\end{array}$ & $\begin{array}{l}\text { - наблюдение за работой } \\
\text { участника обучения } \\
\text { - регулярная оценка (атте- } \\
\text { стация) } \\
\text { - оценка методом «360 гра- } \\
\text { дусов» }\end{array}$ \\
\hline $\begin{array}{l}\text { Динамика резуль- } \\
\text { татов деятельно- } \\
\text { сти предприятия, } \\
\text { финансовый эф- } \\
\text { фект от обучения }\end{array}$ & $\begin{array}{l}\text { - изменение результатов до- } \\
\text { стижения целей участника } \\
\text { обучения, бизнес - показате- } \\
\text { лей структурного подразде- } \\
\text { ления после обучения }\end{array}$ & $\begin{array}{l}\text { - оценка индивидуальных } \\
\text { результатов } \\
\text { - оценка результатов подраз- } \\
\text { деления }\end{array}$ \\
\hline
\end{tabular}


О.Г. Якунина и И.В. Арапова разработали, систематизировали, адаптировали и апробировали показатели оценки эффективности [3; с. 166], актуальные для любого предприятия (рисунок 1).

\begin{tabular}{|c|c|}
\hline $\begin{array}{r}\text { Применяемы } \\
\text { эффективн }\end{array}$ & $\begin{array}{l}\text { ели оценки } \\
\text { низации }\end{array}$ \\
\hline $\begin{array}{l}1 \text { Число обученных работников за } \\
\text { анализируемый период, чел. }\end{array}$ & $\begin{array}{l}2 \text { Доля обученных работников за } \\
\text { анализируемый период, чел. }\end{array}$ \\
\hline $\begin{array}{l}3 \text { Уровень лояльности и } \\
\text { мотивированности персонала }\end{array}$ & $\begin{array}{l}4 \text { Оптимизация внутренних } \\
\text { коммуникаций коллектива }\end{array}$ \\
\hline $\begin{array}{l}5 \text { Обший объем финансовых расходов } \\
\text { на обучение за анализируемый период, } \\
\text { тыс. руб. }\end{array}$ & $\begin{array}{l}5 \text { Доля финансовых расходов на } \\
\text { обучение персонала от общих } \\
\text { расходов на персонал, в \% }\end{array}$ \\
\hline $\begin{array}{l}7 \text { Объем финансовых расходов на } \\
\text { обучение } 1 \text { работника за анализируемый } \\
\text { период }\end{array}$ & 8 Коэффициент текучести кадров, в \% \\
\hline
\end{tabular}

Рис. 1. Показатели оценки эффективности обучения персонала (фрагмент)

Интересна точка зрения бизнес - коуча Е.Н. Ветлужских, основа которой - разделение обучения на краткосрочное и долгосрочное. Это определяет зависимость длительности обучения, показателей и методов оценки его эффективности [4; с. 10], что представлено в таблицах 2 и 3 соответственно.

Таблицуа 2.

Показатели и методы оценки эффективности краткосрочного обучения

\begin{tabular}{|c|c|}
\hline Показатель & Методы оценки \\
\hline $\begin{array}{l}\text { Удовлетворенность обученного } \\
\text { сотрудника приобретенными } \\
\text { знаниями, навыками и качествами }\end{array}$ & $\begin{array}{l}\text { Анкеты оценки обучения заполняются } \\
\text { сотрудниками после обучения }\end{array}$ \\
\hline $\begin{array}{l}\text { Эффективность внесенных обученным } \\
\text { сотрудником предложений по } \\
\text { совершенствованию его деятельности } \\
\text { (подразделения) или выполнение } \\
\text { сотрудником специального задания }\end{array}$ & $\begin{array}{l}\text { Обученный сотрудник выносит } \\
\text { на рассмотрение предложения по } \\
\text { улучшению своей деятельности } \\
\text { (подразделения) }\end{array}$ \\
\hline $\begin{array}{l}\text { Удовлетворенность руководства } \\
\text { обучившегося }\end{array}$ & $\begin{array}{l}\text { Непосредственный руководитель } \\
\text { заполняет анкету оценки } \\
\text { результативности обучения, проводит } \\
\text { оценку в баллах }\end{array}$ \\
\hline
\end{tabular}


Таблицуа 3.

Показатели и методы оценки эффективности долгосрочного обучения

\begin{tabular}{|l|l|}
\hline \multicolumn{1}{|c|}{ Показатель } & \multicolumn{1}{c|}{ Методы оценки } \\
\hline $\begin{array}{l}\text { Приобретение } \\
\text { обучающимся знаний, } \\
\text { навыков и качеств }\end{array}$ & экзамен \\
\hline $\begin{array}{l}\text { Результативность } \\
\text { деятельности } \\
\text { обучаемого }\end{array}$ & $\begin{array}{l}\text { - повышение норм выработки - повышение производи- } \\
\text { тельности } \\
\text { - уменьшение времени на выполнение работ, проектов } \\
\text { (например, проектировщиков) } \\
\text { - повышение объема продаж (для менеджеров, началь- } \\
\text { ника отдела продаж) } \\
\text { - экономия затрат (например, при выполнении проекта) }\end{array}$ \\
\hline
\end{tabular}

Таким образом, рассмотрев точки зрения ученых - исследователей, отметим, что совокупность показателей и методов оценки эффективности обучения персонала разделена на количественные и качественные. Использование количественных методов позволяет определить степень овладения профессиональными знаниями и навыками, что чаще всего проходит в форме экзамена или тестирования. Оценка эффективности обучения персонала качественными методами осуществляется через определенный временной промежуток и носит практическую значимость. При этом определение влияния обучения на параметры деятельности предприятия способствует координации результатов обучения с требованиями функционирования и развития производства. Выбор показателей зависит от целей специалиста, проводящего оценку.

\section{Материалы и методы}

Оценку эффективности обучения персонала на предприятии рекомендуем проводить посредством анализа статистических показателей, контент-анализа, интервью.

Предметная область исследования - предприятие железнодорожного транспорта, входящее в структуру ОАО «Российские железные дороги», основная задача которого - своевременное и качественное выполнение технического обслуживания, ремонта и модернизации локомотивов ОАО «РЖД». 


\section{Результаты и обсуждение}

В таблице 4 представлены статистические показатели, характеризующие обучение персонала в объекте исследования. Отметим, что источником сбора информации явились отчеты об обучении персонала за 2019 и 2020 гг.

Таблицуа 4.

Затраты на обучение персонала предприятия железнодорожного транспорта

\begin{tabular}{|l|c|c|}
\hline \multicolumn{1}{|c|}{ Показатели } & $\mathbf{2 0 1 9}$ г. & $\mathbf{2 0 2 0}$ г. \\
\hline Сумма средств, млн. руб. & 1,304 & 1,15 \\
\hline ФОТ работников, занятых в основной период, млн. руб. & 59,4 & 58,933 \\
\hline \% средств от ФОТ, затраченных на обучение персонала & 2,2 & 1,95 \\
\hline
\end{tabular}

Руководствуясь данными таблицы 4, отметим, что предприятие вкладывает значительные финансовые средства в развитие персонала. Так, в 2019 году на обучение затрачено 1,304 млн. руб., в 2020 г. - 1,15 млн. руб. Однако, наблюдается отрицательная динамика финансовых инвестиций. Это связано с реструктуризацией и сопутствующим сокращением персонала на предприятии.

Далее в таблице 5 представлено количество обученных сотрудников предприятия за 2019-2020 гг.

Таблицуа 5.

Количество обученных сотрудников предприятия железнодорожного транспорта

\begin{tabular}{|l|c|c|c|c|}
\hline \multirow{2}{*}{ Показатели } & \multicolumn{2}{|c|}{$\mathbf{2 0 1 9}$ г. } & \multicolumn{2}{c|}{$\mathbf{2 0 2 0}$ г. } \\
\cline { 2 - 5 } & план & факт & план & факт \\
\hline Численность работников & 215 & 219 & 220 & 222 \\
\hline
\end{tabular}

На основании данных, представленных в таблице 5, можно сделать вывод о том, что в рассматриваемый период количество обученных сотрудников предприятия незначительно превышает плановую величину. В частности, на 4 и 2 сотрудника в 2019 г. и 2020 г. соответственно. Это связано с неверным определением потребности в обучении персонала на предприятии. Следствие - некорректный комплексный план развития и обучения.

Основные направления обучения персонала на предприятии в 2019-2020 гг. - это «Поверка и калибровка средств теплотехниче- 
ских измерений», «Безопасные методы и приемы выполнения работ на высоте», «Поверка и калибровка геометрических средств», «Охрана труда», «Метрологическое обеспечение», «Электромеханик по средствам автоматики и приборам технологического оборудования», «Устройство, алгоритм и техническое обслуживание микропроцессорного дешифратора ДКСВ-М».

Особый интерес представляют поставщики образовательных услуг для предприятия железнодорожного транспорта в 2019-2020 гг. Это Иркутский государственный университет путей сообщения, Российский университет транспорта, Межотраслевой учебный центр «Кадры», ООО «Экология транспорта», Сибирский федеральный университет, Ижевский радиозавод «Локомотив Ижевск», Автотранспортный техникум, Академия стандартизации, метрологии и сертификации.

Таким образом, обучение занимает важное место в системе управления персоналом предприятия. Это подтверждает заинтересованность работодателя в развитии персонала, что непосредственно отражается на эффективности их профессиональной деятельности.

Далее рассмотрим регламенты по обучению персонала на предприятии. В этой связи отметим, что обучение проводится в соответствии со Стандартом по качеству ОАО «РЖД» «Обучение и повышение квалификации персонала».

Стандарт соответствует рекомендуемой структуре локального документа, регламентирующего обучение персонала на предприятии, поскольку в качестве основных разделов определены «Область применения», «Цель», «Определение понятий», «Общие положения и схема процесса обучения и повышения квалификации», «Процесс обучение и повышение квалификации персонала».

Согласно Стандарту порядок реализации обучения и повышения квалификации персонала предприятия включает [11]:

- оценку потребности в персонале и его обучении;

- формирование плана обучения персонала;

- проведение обучения персонала и проверки знаний по его результатам; 
- анализ эффективности применения знаний обученными сотрудниками и документирование результатов обучения;

- оценка эффективности обучения.

Оценка эффективности обучения осуществляется в конкретном структурном подразделении не реже 1 раза в год. Отслеживаются изменения в профессиональной деятельности обученных сотрудников. Например, в виде экзамена, на основании которого фиксируются результаты обучения.

Далее представим ответы на вопросы, полученные в ходе интервью с начальниками производственных участков предприятия, подчиненные которых согласно плану регулярно проходят обучение.

На вопрос о том, как часто проходит обучение, респонденты ответили, что регулярно. В соответствии с потребностью в обучении формируются группы, которые направляются, в том числе в Учебные центры ОАО «РЖД». Дополнительно внепланово обучают новых работников предприятия.

На вопрос о применении полученных знаний руководители обозначили проблему. Часто полученные знания применимы в одной ситуации, но неприемлемы для другой. Следовательно, не всегда содержание обучения совпадает с содержанием профессиональной деятельности. Иными словами программы обучения не всегда соответствуют актуальным запросам производственных задач.

Раскрывая ответ на вопрос о критериях оценки эффективности обучения, руководители акцентировали внимание на том, что в принципе на предприятии процедура оценки эффективности отсутствует. Следовательно, критериев нет.

Определяя показатели результативности обучения, респонденты отметили, что результаты обучения измеряются в соответствующем учебном подразделении при сдаче экзаменов и других выходных мероприятий. На предприятии такие показатели отсутствуют.

Ответ на вопрос о показателях деятельности предприятия определил их прямую взаимосвязь с качественным обучением персонала. Малейшее отклонение от технологии - это причина аварии. Следовательно, актуальна компетентность персонала в вопросах 
технического устройства приборов, безопасности подвижного состава. Показатели деятельности, требующие актуальные знания, - это уменьшение количества отказов первой и второй категории, сбоев, сокращение нарушений в работе скоростемеров.

На вопрос о путях повышения эффективности обучения респондентами высказано мнение, что необходимы показатели, соответствующие профессиональной деятельности персонала. Это обеспечит повышение уровня их мотивации к обучению и достижения организационных целей [1]. Особо ценным является то, что показатели эффективности отражают возвратность финансовых вложений на обучение персонала предприятия.

Таким образом, оценка эффективности обучения персонала на предприятии железнодорожного транспорта формальна, следствием чего является наличие проблем. В частности, это отсутствие целеполагания в обучении. Показателей и критериев измерения полученного результата нет.

Рекомендуемые показатели оценки эффективности обучения персонала для предприятий железнодорожного транспорта представлены в таблице 6.

Таблицуа 6.

Показатели и критерии оценки эффективности обучения персонала для предприятий железнодорожного транспорта

\begin{tabular}{|c|c|c|}
\hline Показатель & $\begin{array}{c}\text { Алгоритм } \\
\text { определения }\end{array}$ & Критерии \\
\hline $\begin{array}{l}\text { Выполнение плана обуче- } \\
\text { ния - сравнение фактиче- } \\
\text { ского и планового количе- } \\
\text { ства обученных }\end{array}$ & $\frac{\Psi_{\Phi}}{Ч_{\Pi}} * 100 \%$ & $\begin{array}{l}\text { 0-55\% - невыполнение плана } \\
56-75 \% \text { - частичное выполнение плана } \\
76-100 \% \text { - выполнение плана }\end{array}$ \\
\hline $\begin{array}{l}\text { Затраты на обучение пер- } \\
\text { сонала - определение про- } \\
\text { цента затрат на обучение от } \\
\text { фонда оплаты труда }\end{array}$ & $\frac{30}{\Phi 0 \mathrm{~T}} * 100 \%$ & $\begin{array}{l}0-2 \% \text { - уровень затрат минимальный } \\
2-5 \% \text { - уровень затрат оптимальный }\end{array}$ \\
\hline Индекс лояльности & $\begin{array}{l}\text { Employee Net } \\
\text { Promoter Score }\end{array}$ & $\begin{array}{l}0-55 \% \text { - программу обучения необходи- } \\
\text { мо заменить } \\
56-75 \% \text { - программа обучения требует } \\
\text { корректировки } \\
76-100 \% \text { - программа обучения соответ- } \\
\text { ствует целям и задачам }\end{array}$ \\
\hline
\end{tabular}


Окончание табл. 6.

\begin{tabular}{|c|c|c|}
\hline $\begin{array}{l}\text { Удовлетворенность руко- } \\
\text { водителя обучением пер- } \\
\text { сонала }\end{array}$ & $\begin{array}{l}\text { Анкета } \\
\text { Е.Н. Ветлуж- } \\
\quad \text { ских }\end{array}$ & $\begin{array}{l}0-50 \% \text { - руководитель полностью не- } \\
\text { удовлетворен обучением персонала } \\
51-70 \% \text { - руководитель частично удов- } \\
\text { летворен обучением персонала } \\
71-100 \% \text { - руководитель полностью } \\
\text { удовлетворен обучением персонала } \\
\end{array}$ \\
\hline $\begin{array}{l}\text { Использование полученных } \\
\text { знаний в профессиональной } \\
\text { деятельности - отношение } \\
\text { количества внесенных ра- } \\
\text { циональных предложений к } \\
\text { числу обученных по отдель- } \\
\text { ной программе }\end{array}$ & $\frac{\text { Чрп }}{\text { Чобуч }} * 100 \%$ & $\begin{array}{l}0-55 \% \text { - программа обучения не соот- } \\
\text { ветствует практической деятельности } \\
56-75 \% \text { - программа частично соответ- } \\
\text { ствует практической деятельности } \\
76-100 \% \text { - программа полностью соот- } \\
\text { ветствует практической деятельности }\end{array}$ \\
\hline $\begin{array}{l}\text { Повышение производи- } \\
\text { тельности труда - увеличе- } \\
\text { ние уровня и темпов роста } \\
\text { производительности труда } \\
\text { в сравнении с прошлым } \\
\text { периодом, без учета иных } \\
\text { факторов } \\
\end{array}$ & $\frac{\Pi \mathrm{T} 1}{\Pi \mathrm{T} 0} * 100 \%$ & $\begin{array}{l}0-2 \% \text { - увеличение несущественное } \\
3-5 \% \text { - увеличение существенное }\end{array}$ \\
\hline $\begin{array}{l}\text { Технологические наруше- } \\
\text { ния по вине работников - } \\
\text { оценивается количество } \\
\text { технологических наруше- } \\
\text { ний по вине работников до } \\
\text { обучения и после } \\
\end{array}$ & \multicolumn{2}{|c|}{$\begin{array}{l}\text { Сохранение или увеличение количества технологических } \\
\text { нарушений - обучение не оказывает влияния на деятель- } \\
\text { ность предприятия и неэффективно для него } \\
\text { Уменьшение количества технологических нарушений - об- } \\
\text { учение оказывает положительное влияние на деятельность } \\
\text { предприятия. }\end{array}$} \\
\hline $\begin{array}{l}\text { Процент возврата аппарату- } \\
\text { ры в гарантийный период - } \\
\text { оценивается количество воз- } \\
\text { врата отремонтированной } \\
\text { аппаратуры в определенный } \\
\text { гарантийный срок }\end{array}$ & \multicolumn{2}{|c|}{$\begin{array}{l}\text { Сохранение количества возврата аппаратуры - обучение не } \\
\text { оказывает влияния на качество труда. } \\
\text { Уменьшение количества возврата аппаратуры - обучение } \\
\text { оказывает положительное влияние на качество труда }\end{array}$} \\
\hline $\begin{array}{l}\text { Отказы технических } \\
\text { средств - оценивается коли- } \\
\text { чество отказов технических } \\
\text { средств «до» и «после» об- } \\
\text { учения }\end{array}$ & \multicolumn{2}{|c|}{$\begin{array}{l}\text { Сохранение или рост количества случаев отказа техниче- } \\
\text { ских средств - обучение не оказывает влияния на деятель- } \\
\text { ность предприятия. } \\
\text { Уменьшение количества случаев отказа технических } \\
\text { средств - обучение оказывает положительное влияние на } \\
\text { деятельность предприятия. }\end{array}$} \\
\hline
\end{tabular}

\section{Заключение}

Итак, согласно цели исследования, сформулируем основные ВЫВоды.

Во-первых, выявлены значимость, актуальность и проблемы, обусловленные трудоемкостью оценки эффективности обучения персонала. Показатели и методы оценки эффективности должны соответствовать целям и задачам обучения для конкретного предприятия. 
Во-вторых, определены проблемы при оценке эффективности обучения персонала на предприятии железнодорожного транспорта - это отсутствие показателей и критериев измерения полученного результата.

B-третьих, предложены показатели оценки эффективности обучения персонала для предприятий железнодорожного транспорта - выполнение плана обучения, затраты на обучение персонала, индекс лояльности работника, удовлетворенность руководителя обучением персонала, использование полученных знаний в профессиональной деятельности, повышение производительности труда, процент возврата аппаратуры в гарантийный период, отказы технических средств.

\section{Список литературы}

1. Алексахина Ю.В. Оценка экономической эффективности вложений в персонал // Экономические аспекты развития российской индустрии в условиях глобализации: Материалы Международной научно-практической конференции кафедры «Экономика и организация производства». 2015. С. 286-290.

2. Алексеева Т.Н. Оценка эффективности организационного обучения на основе компетентностного подхода // Вестник Новосибирского государственного университета. Серия: Социально-экономические науки. 2007. Т. 7, № 2. С. 153-157.

3. Вашко Т.А., Максименко И.А., Шендель Т.В., Якимова Л.Д., Яркова С.А. Обучение персонала как инструмент развития человеческого потенциала в условиях цифровой трансформации: монография. Красноярск: Красноярский институт железнодорожного транспорта. 2021. 205 c.

4. Ветлужских Е.Н. Обучаем - оцениваем. Модели критериальной оценки результатов обучения // Справочник по управлению персоналом. 2005. № 2. С. 10-18.

5. Груздева О.Г. Подготовка инженеров железнодорожного транспорта в странах ЕЭС (на примере Германии и Великобритании) // Педагогическое образование в России. 2012. № 4. 
C. 117-120. https://pedobrazovanie.ru/archive/1/4/podgotovkainzhenerov-zheleznodorozhnogo-transporta-v-stranakh-ees-na-primeregermanii-i-velikobritanii

6. Данилова А.С., Яркова С.А., Пугачёва Я.А. Обучение как один из основных элементов развития персонала // Проблемы и пути развития профессионального образования: сборник статей Всероссийской научно-методической конференции. 2019. С. 103-106.

7. Куприянова О.О., Шендель Т.В. О стратегическом развитии предприятий железнодорожного транспорта // Актуальные проблемы авиации и космонавтики: материалы V Международной научнопрактической конференции, посвященной Дню космонавтики / СибГУ им. М.Ф. Решетнева. Красноярск. 2019. Т. 3. С. 301-303.

8. Кутузова А.В., Краснова Е.С. Методы оценки эффективности системы обучения персонала на предприятиях в современных условиях // Молодёжь Сибири - науке России: материалы международной научно-практической конференции. 2018. С. 120-123.

9. Маслова В.М. Управление персоналом: учебник. М.: Юрайт, 2015. $492 \mathrm{c}$.

10. Награльян А. Оценка и развитие работников: вектор на опережение: [Новая кадровая стратегия ОАО «РЖД»] // Справочник по управлению персоналом. 2013. № 8. С. 29-34.

11. О профессиональном обучении рабочих кадров открытого акционерного общества «Российские железные дороги»: положение РЖД от 11.01.2006 № BM-137. http://doc.rzd.ru/doc/public/ru?STRUCTURE_ $\mathrm{ID}=704$ \&layer_id $=5104 \& \mathrm{id}=3735$

12.Пермякова С.А., Шендель Т.В. Изменение системы обучения административно-управленческого персонала компании // Управление человеческими ресурсами - основа развития инновационной экономики: материалы VII Международной научно-практической конференции. 2017. № 7. С. 392-400.

13. Соколова Е.Л., Рудая Т.А. Эффективность обучения: проблемы и ответственность // Управление человеческими ресурсами - основа развития инновационной экономики: материалы II Международной научно-практической конференции. 2010. № 2. С. 373-374. 
14. Щербакова А.В., Серикова О.Ю. К вопросу об оценке эффективности обучения персонала // Современная экономика и общество глазами молодых исследователей: сборник статей участников Международной научно-практической конференции $\mathrm{V}$ Уральского вернисажа науки и бизнеса: в 3 томах. 2018. С. 305-309.

15. Якимова Л.Д., Гераль К.А. Совершенствование программ обучения в условиях внедрения профессиональных стандартов // Актуальные проблемы социально-экономического развития России: сборник по материалам IX Международной научно-практической конференции. 2019. C. 323-335.

16. Яркова С.А., Пугачева Я.А. Методы оценки системы развития персонала в организации // Наукоемкие исследования как основа инновационного развития общества: сборник статей Международной научно-практической конференции. 2019. С. 209-213.

17. Gyurova V., Popova L. Possibilities of employers for staff training // Pedagogy. 2018, vol. 90, no. 3, pp. 373-383. https://pedagogy.azbuki.bg/pedagogics/pedagogyarticle/pedagogyarticle2016-3/xc-32018/\#art05

18. Ilyushnikov K.K., Lobova S.V. Evaluation model for effectiveness of corporate training based on key performance indicators and detailed metrics // Espacios, 2019, vol. 40, no. 1. http://www.revistaespacios.com/ a19v40n01/a19v40n01p29.pdf

19. Innovative approach for evaluating training effectiveness / Daniali S., Khortabi F.M., Mohammadbeiki Y. // Proceedings of the 32nd International Business Information Management Association Conference, IBIMA 2018 - Vision 2020: Sustainable Economic Development and Application of Innovation Management from Regional expansion to Global Growth. 32, Vision 2020: Sustainable Economic Development and Application of Innovation Management from Regional Expansion to Global Growth, 2018, pp. 818-830.

20. Staff satisfaction with the training system at the stage of identity / Vinichenko M.V., Li N.P., Melnichuk A.V., Chulanova O.L., Borisenko N. S. // Espacios, 2019, vol. 40, no. 34, pp. 1-15. https://www.revistaespacios.com/a19v40n34/a19v40n34p08.pdf 


\section{References}

1. Aleksahina Yu.V. Ekonomicheskie aspekty razvitiya rossijskoj industrii $v$ usloviyah globalizacii [Economic aspects of the development of the Russian industry in the context of globalization]: Materials of the International Scientific and Practical Conference of the Department of Economics and Organization of Production, 2015, pp. 286-290.

2. Alekseeva T.N. Vestnik Novosibirskogo gosudarstvennogo universiteta. Seriya: Social'no-ekonomicheskie nauki [Bulletin of the Novosibirsk State University. Series: Socio-economic sciences], 2007, vol. 7, no. 2, pp. 153-157.

3. Vashko T.A., Maksimenko I.A., SHendel' T.V., YAkimova L.D., YArkova S.A. Obuchenie personala kak instrument razvitiya chelovecheskogo potenciala $v$ usloviyah cifrovoj transformacii [Personnel training as a tool for human development in the context of digital transformation]: monograph. Krasnoyarsk: Krasnoyarskij institut zheleznodorozhnogo transporta, 2021, $205 \mathrm{p}$.

4. Vetluzhskih E.N. Spravochnik po upravleniyu personalom [Handbook of Human Resources Management], 2005, no. 2, pp. 10-18.

5. Gruzdeva O.G. Pedagogicheskoe obrazovanie v Rossii [Teacher education in Russia], 2012, no. 4, pp. 117-120. https://pedobrazovanie. $\mathrm{ru} /$ archive/1/4/podgotovka-inzhenerov-zheleznodorozhnogo-transporta-v-stranakh-ees-na-primere-germanii-i-velikobritanii

6. Danilova A.S., YArkova S.A., Pugachyova YA.A. Problemy i puti razvitiya professional'nogo obrazovaniya: sbornik statej Vserossijskoj nauchno-metodicheskoj konferencii [Problems and ways of professional education development: collection of articles of the All-Russian Scientific and Methodological Conference], 2019, pp. 103-106.

7. Kupriyanova O.O., SHendel' T.V. Aktual'nye problemy aviacii i kosmonavtiki: materialy VMezhdunarodnoj nauchno-prakticheskoj konferencii, posvyashchennoj Dnyu kosmonavtiki [Actual problems of aviation and cosmonautics: materials of the V International Scientific and Practical Conference dedicated to the Day of Cosmonautics]. Krasnoyarsk, 2019, vol. 3, pp. 301-303. 
8. Kutuzova A.V., Krasnova E.S. Molodyozh'Sibiri-nauke Rossii: materialy mezhdunarodnoj nauchno-prakticheskoj konferencii [Youth of Siberia - to the science of Russia: materials of the international scientific and practical conference], 2018, pp. 120-123.

9. Maslova V.M. Upravlenie personalom: uchebnik [Personnel Management: tutorial]. M.: Yurajt, 2015, 492 p.

10. Nagral'yan A. Spravochnik po upravleniyu personalom [Handbook of Human Resources Management], 2013, no. 8, pp. 29-34.

11. O professional'nom obuchenii rabochih kadrov otkrytogo akcionernogo obshchestva "Rossijskie zheleznye dorogi": polozhenie RZHD ot 11.01.2006 № VM-137 [About professional training of workers of open Joint Stock Company "Russian Railways": Regulations of Russian Railways of 11.01.2006 No. VM-137]. http://doc.rzd.ru/doc/public/ru?STRUCTURE_ID=704\&layer_id=5104\&id=3735

12. Permyakova S.A., Shendel' T.V. Upravlenie chelovecheskimi resursamiosnova razvitiya innovacionnoj ekonomiki: materialy VII Mezhdunarodnoj nauchno-prakticheskoj konferencii [Human Resource Management - the basis for the development of an innovative economy: proceedings of the VII International Scientific and Practical Conference], 2017, no. 7, pp. 392-400.

13. Sokolova E.L., Rudaya T.A. Upravlenie chelovecheskimi resursami osnova razvitiya innovacionnoj ekonomiki: materialy II Mezhdunarodnoj nauchno-prakticheskoj konferencii [Human Resource Management - the basis for the development of an innovative economy: proceedings of the II International Scientific and Practical Conference], 2010, no. 2, pp. 373-374.

14. Shcherbakova A.V., Serikova O.Yu. Sovremennaya ekonomika i obshchestvo glazami molodyh issledovatelej: sbornik statej uchastnikov Mezhdunarodnoj nauchno-prakticheskoj konferencii V Ural'skogo vernisazha nauki i biznesa: $v 3$ tomah [Modern Economy and society through the eyes of young researchers: a collection of articles by participants of the International Scientific and Practical Conference of the V Ural Vernissage of Science and Business: in 3 volumes]. 2018. pp. $305-309$.

15. Yakimova L.D., Geral' K.A. Aktual'nye problemy social'no-ekonomicheskogo razvitiya Rossii: sbornik po materialam IX Mezhdunarodnoj 
nauchno-prakticheskoj konferencii [Actual problems of socio-economic development of Russia: collection of materials of the IX International Scientific and Practical Conference], 2019, pp. 323-335.

16. Yarkova S.A., Pugacheva Ya.A. Naukoemkie issledovaniya kak osnova innovacionnogo razvitiya obshchestva: sbornik statej Mezhdunarodnoj nauchno-prakticheskoj konferencii [High-tech research as a basis for innovative development of society: collection of articles of the International Scientific and Practical Conference]. 2019. pp. 209-2013.

17. Gyurova V., Popova L. Pedagogy, 2018, vol. 90, no. 3, pp. 373-383. https://pedagogy.azbuki.bg/pedagogics/pedagogyarticle/pedagogyarticle2016-3/xc-3-2018/\#art05

18. Ilyushnikov K.K., Lobova S.V. Espacios, 2019, vol. 40, no. 1. http:// www.revistaespacios.com/a19v40n01/a19v40n01p29.pdf

19. Daniali S., Khortabi F.M., Mohammadbeiki Y. Proceedings of the 32nd International Business Information Management Association Conference, IBIMA 2018 - Vision 2020: Sustainable Economic Development and Application of Innovation Management from Regional expansion to Global Growth. 32, Vision 2020: Sustainable Economic Development and Application of Innovation Management from Regional Expansion to Global Growth, 2018, pp. 818-830.

21. Vinichenko M.V., Li N. P., Melnichuk A.V., Chulanova O.L., Borisenko N.S. Espacios, 2019, vol. 40, no. 34, pp. 1-15. https://www.revistaespacios.com/a19v40n34/a19v40n34p08.pdf

\section{ДАННЫЕ ОБ АВТОРАХ}

Шендель Татьяна Владимировна, доцент, кандидат педагогических наук, доцент кафедры экономики труда и управления персоналом

Сибирский государственный университет науки и технологий имени академика М.Ф. Решетнева

проспект им. газеты Красноярский рабочий, 31, г. Красноярск, 660037, Российская Федерачия

Shendeltatjana@rambler.ru 
Яркова Светлана Анатольевна, доцент, кандидат технических наук, доцент кафедры управления персоналом Красноярский институт железнодорожного транспорта филиал Иркутского университета путей сообщения ул. Ладо Кеиховели, 89, г. Красноярск, 660028, Российская Федераичя

yarkova_sa@krsk.irgups.ru

\section{DATA ABOUT THE AUTHORS}

Shendel Tatyana Vladimirovna, Associate Professor, Candidate of Pedagogical Sciences, Associate Professor of the Department of labor Economics and personnel management Reshetnev Siberian State University of Science and Technology 31, prospect named after the newspaper Krasnoyarsk worker, Krasnoyarsk, 660037, Russian Federation

Shendeltatjana@rambler.ru

SPIN-code: 8790-3327

ORCID: 0000-0003-0336-3707

Yarkova Svetlana Anatol'evna, Associate Professor, Candidate of Technical Sciences, Associate Professor of the Department of Personnel Management

Krasnoyarsk Institute of Railway Transport - branch of the Irkutsk University of Railway Transport

89, Lado Ketskhoveli Str., Krasnoyarsk, 660028, Russian Federation

yarkova_sa@krsk.irgups.ru

SPIN-code: 2762-3908

ORCID: 0000-0002-4488-0930 